Supplement of Clim. Past, 11, 939-958, 2015

http://www.clim-past.net/11/939/2015/

doi:10.5194/cp-11-939-2015-supplement

(C) Author(s) 2015. CC Attribution 3.0 License.

(c) (i)

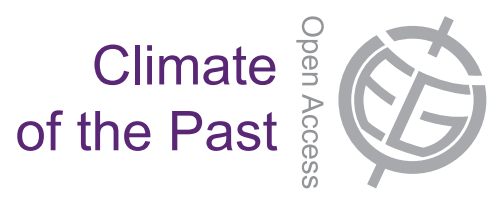

Supplement of

\title{
Reconciling reconstructed and simulated features of the winter Pacific/North American pattern in the early 19th century
}

D. Zanchettin et al.

Correspondence to: D. Zanchettin (davide.zanchettin@mpimet.mpg.de)

The copyright of individual parts of the supplement might differ from the CC-BY 3.0 licence. 

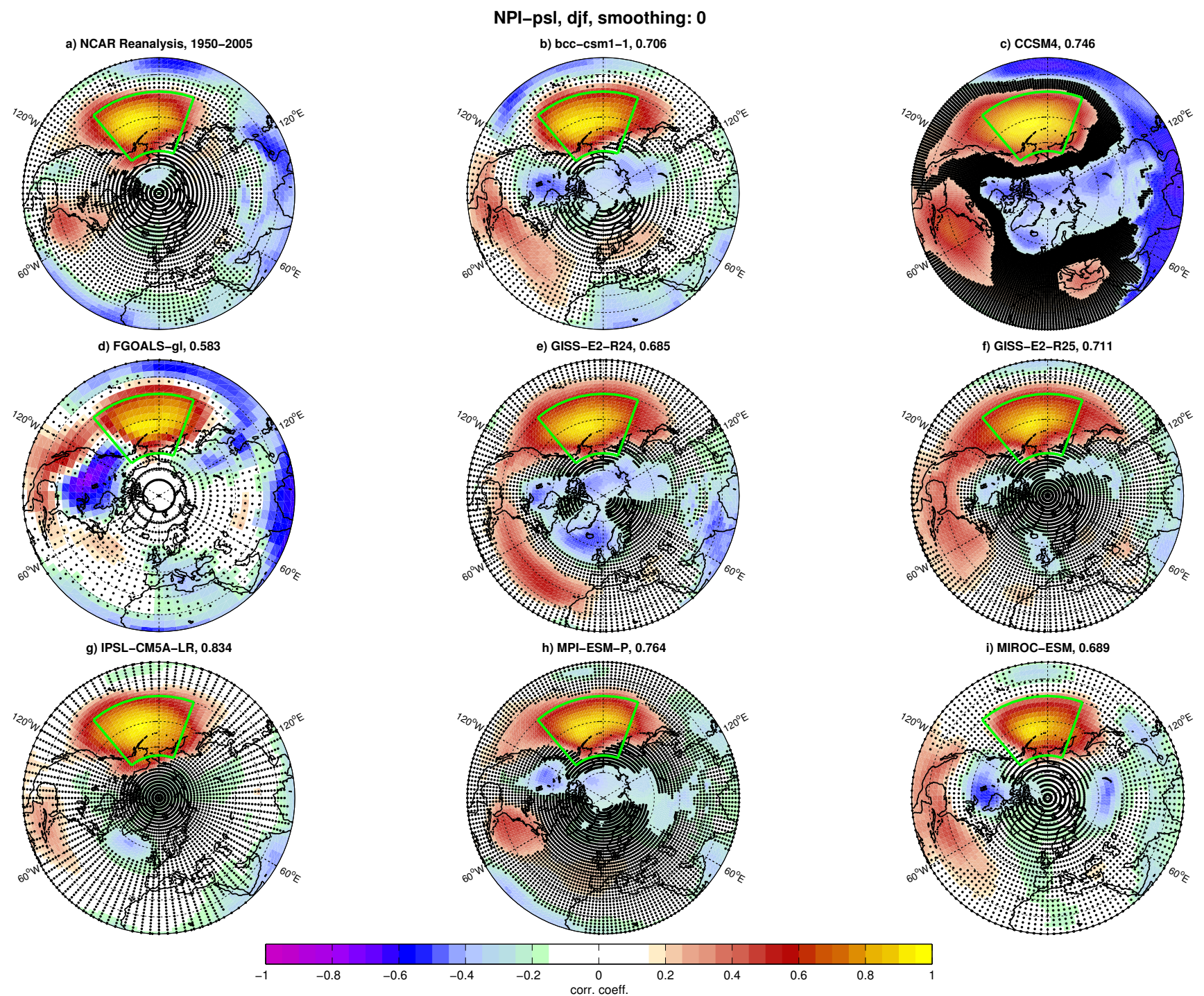

Figure S1 - Observed and simulated correlation maps between the winter NPI index and winter sealevel pressure time series for the period 1950-2005. Dots mark grid points where the correlation is not significant at $95 \%$ confidence accounting for autocorrelation. The green contour marks the domain used for the calculation of the NPI index. In panels b-i, the numbers reported in the title are the spatial correlations between observed and simulated patterns calculated for the domain north of $20^{\circ} \mathrm{N}$ (to this purpose NCAR data were regridded to the model grid). 


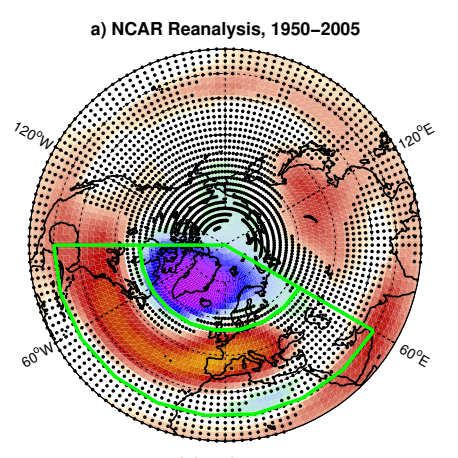

NAO-zg500, djf, smoothing: 0
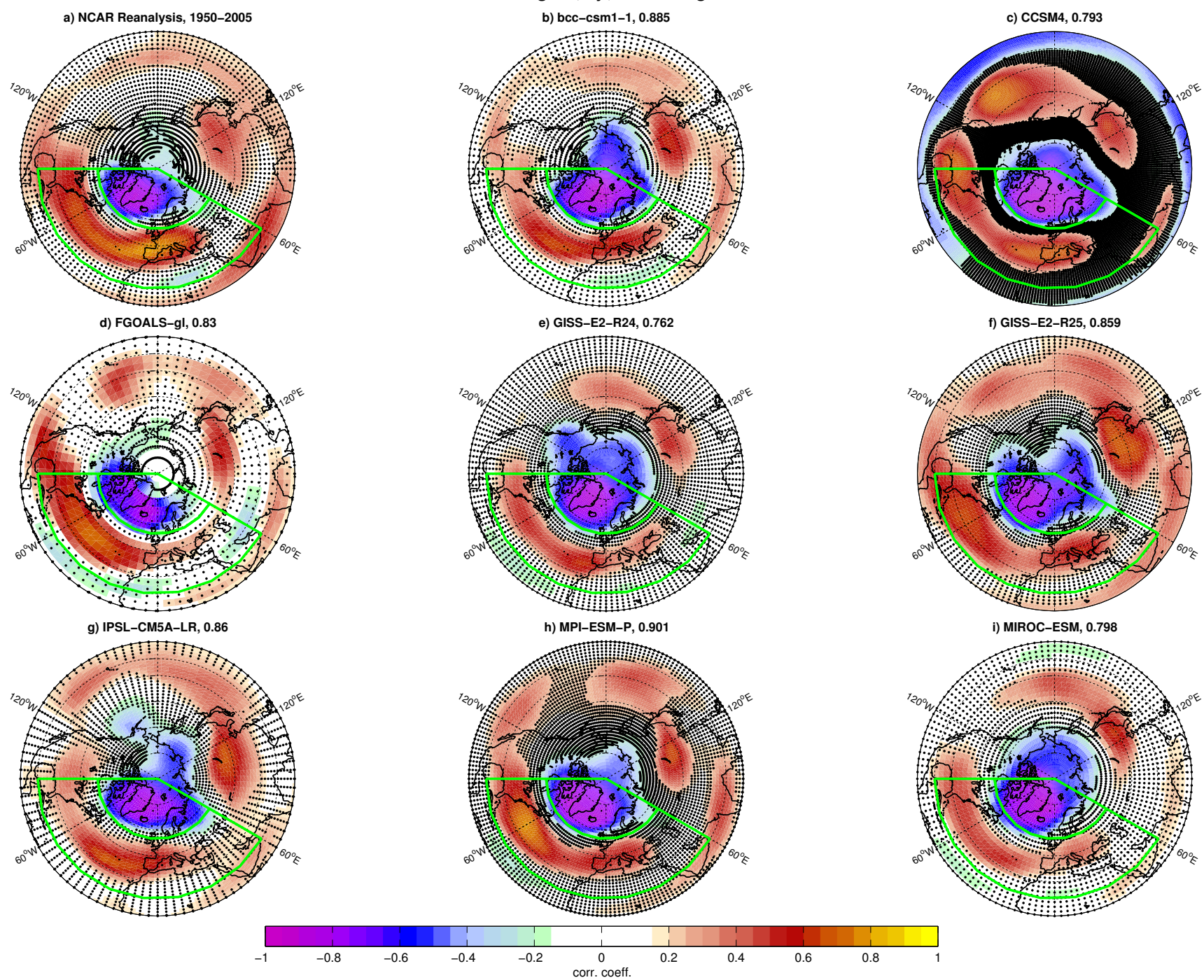

Figure S2 - Observed and simulated correlation maps between the winter NAO index and winter Z500 time series for the period 1950-2005. Dots mark grid points where the correlation is not significant at 95\% confidence accounting for autocorrelation. The green contours mark the boxes used for the calculation of the NAO index. In panels b-i, the numbers reported in the title are the spatial correlations between observed and simulated patterns calculated for the domain north of $20^{\circ} \mathrm{N}$ (to this purpose NCAR data were regridded to the model grid). 
sol-psl, djf, smoothing: 0
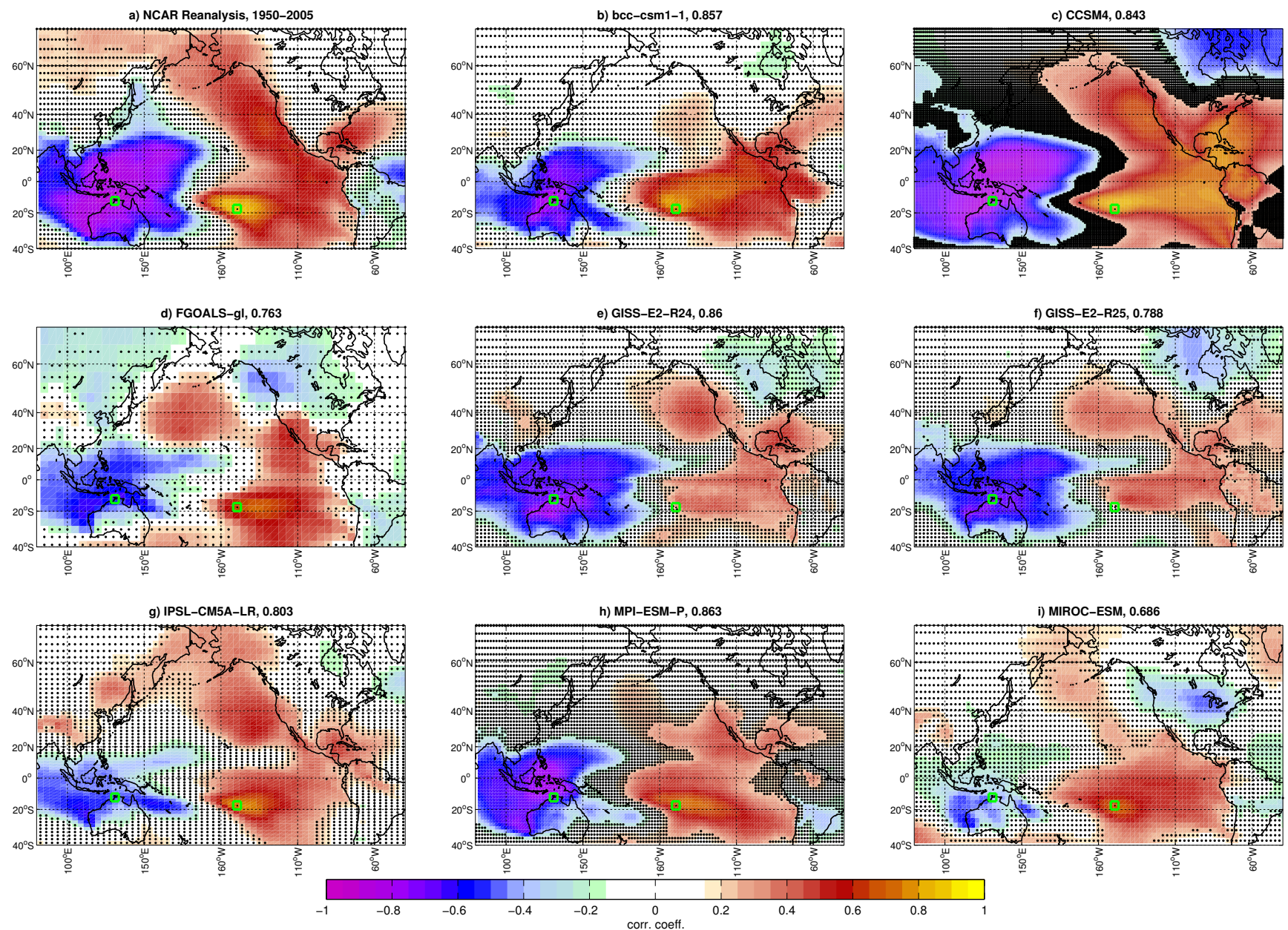

Figure S3 - Observed and simulated correlation maps between the winter SOI index and winter sealevel pressure time series for the period 1950-2005. Dots mark grid points where the correlation is not significant at 95\% confidence accounting for autocorrelation. The green contours mark the boxes used for the calculation of the SOI index. In panels b-i, the numbers reported in the title are the spatial correlations between observed and simulated patterns calculated for the shown domain north of $30^{\circ} \mathrm{S}$ (to this purpose NCAR data were regridded to the model grid). 

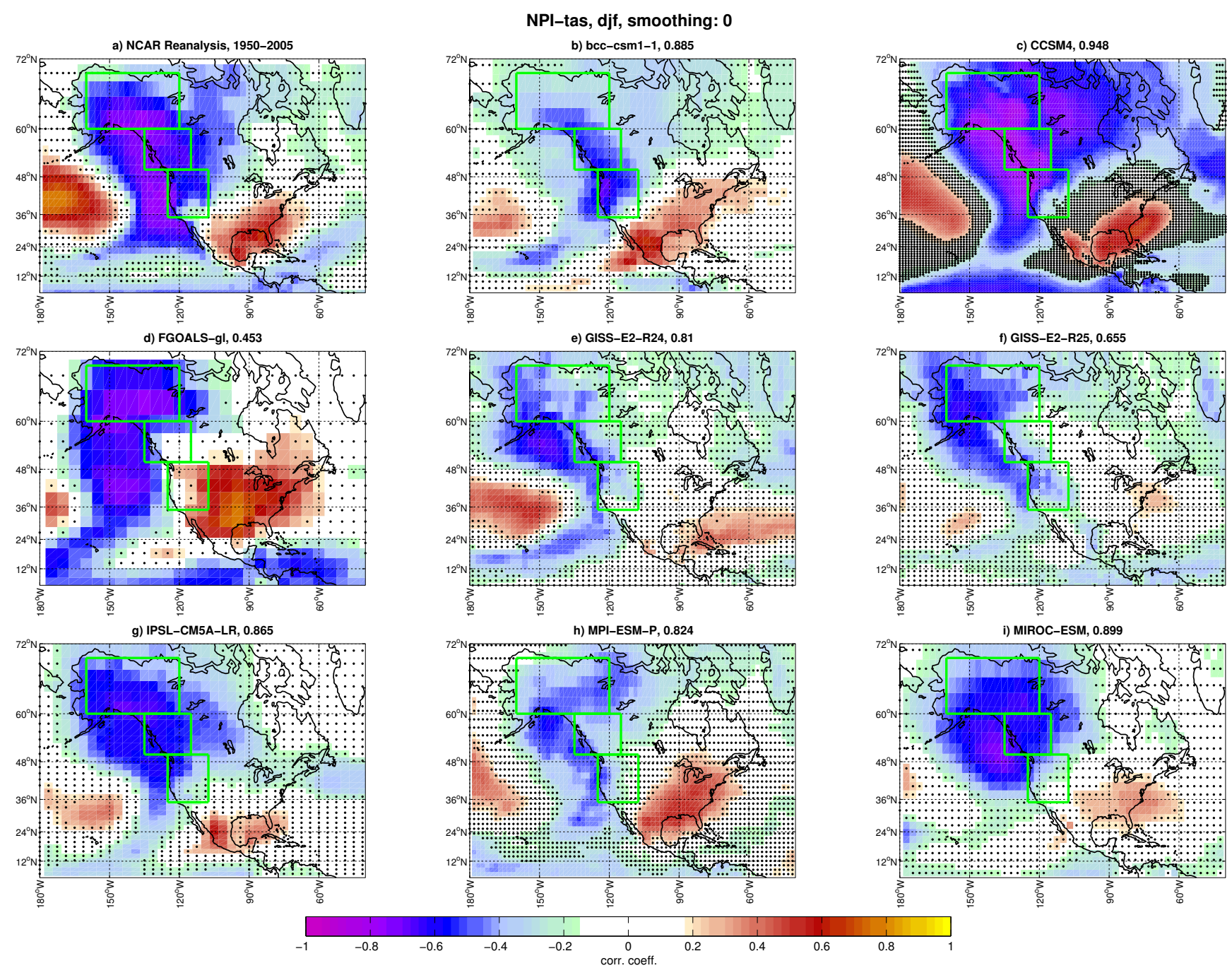

Figure S4 - Observed and simulated correlation maps between the winter NPI index and winter surface-air-temperature time series for the period 1950-2005. Dots mark grid points where the correlation is not significant at $95 \%$ confidence accounting for autocorrelation. The green contours mark the boxes used for the TT2010 reconstruction. In panels b-i, the numbers reported in the title are the spatial correlations between observed and simulated patterns calculated for the shown land-only domain north of $12^{\circ} \mathrm{N}$ (to this purpose NCAR data were regridded to the model grid). 

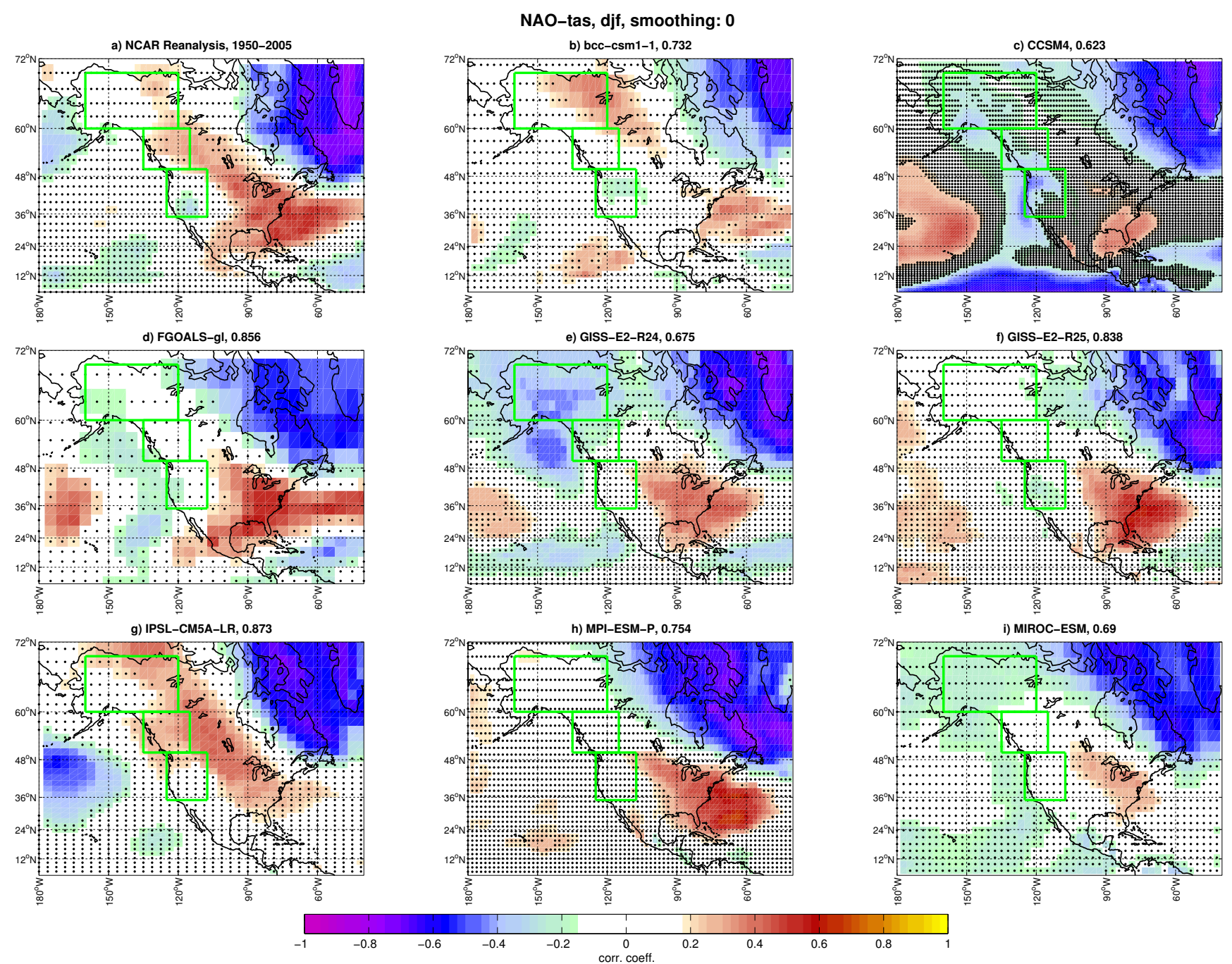

Figure S5 - Observed and simulated correlation maps between the winter NAO index and winter surface-air-temperature time series for the period 1950-2005. Dots mark grid points where the correlation is not significant at $95 \%$ confidence accounting for autocorrelation. The green contours mark the boxes used for the TT2010 reconstruction. In panels b-i, the numbers reported in the title are the spatial correlations between observed and simulated patterns calculated for the shown land-only domain north of $12^{\circ} \mathrm{N}$ (to this purpose NCAR data were regridded to the model grid). 

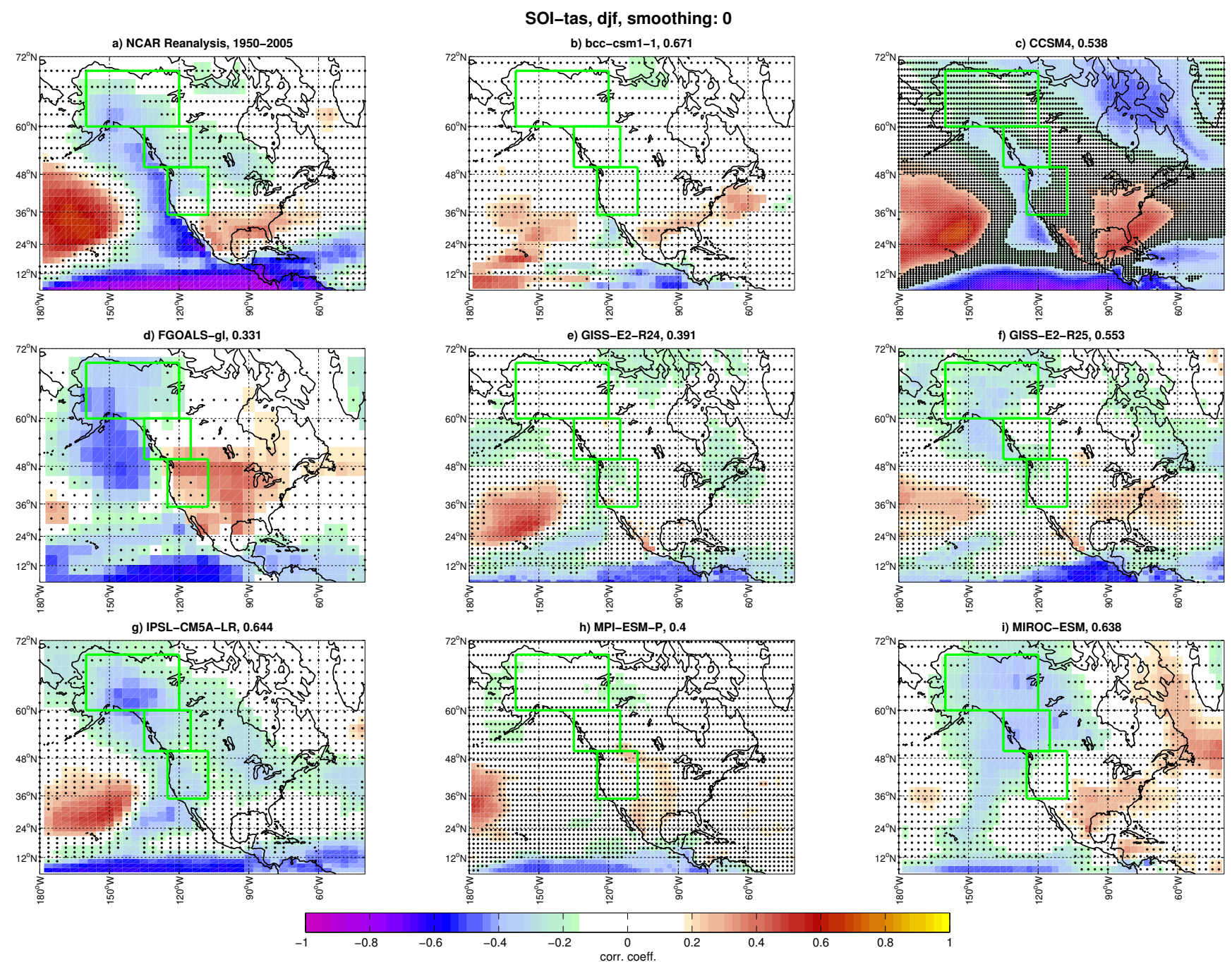

Figure S6 - Observed and simulated correlation maps between the winter SOI index and winter surface-air-temperature time series for the period 1950-2005. Dots mark grid points where the correlation is not significant at $95 \%$ confidence accounting for autocorrelation. The green contours mark the boxes used for the TT2010 reconstruction. T In panels b-i, the numbers reported in the title are the spatial correlations between observed and simulated patterns calculated for the shown land-only domain north of $12^{\circ} \mathrm{N}$ (to this purpose NCAR data were regridded to the model grid). 

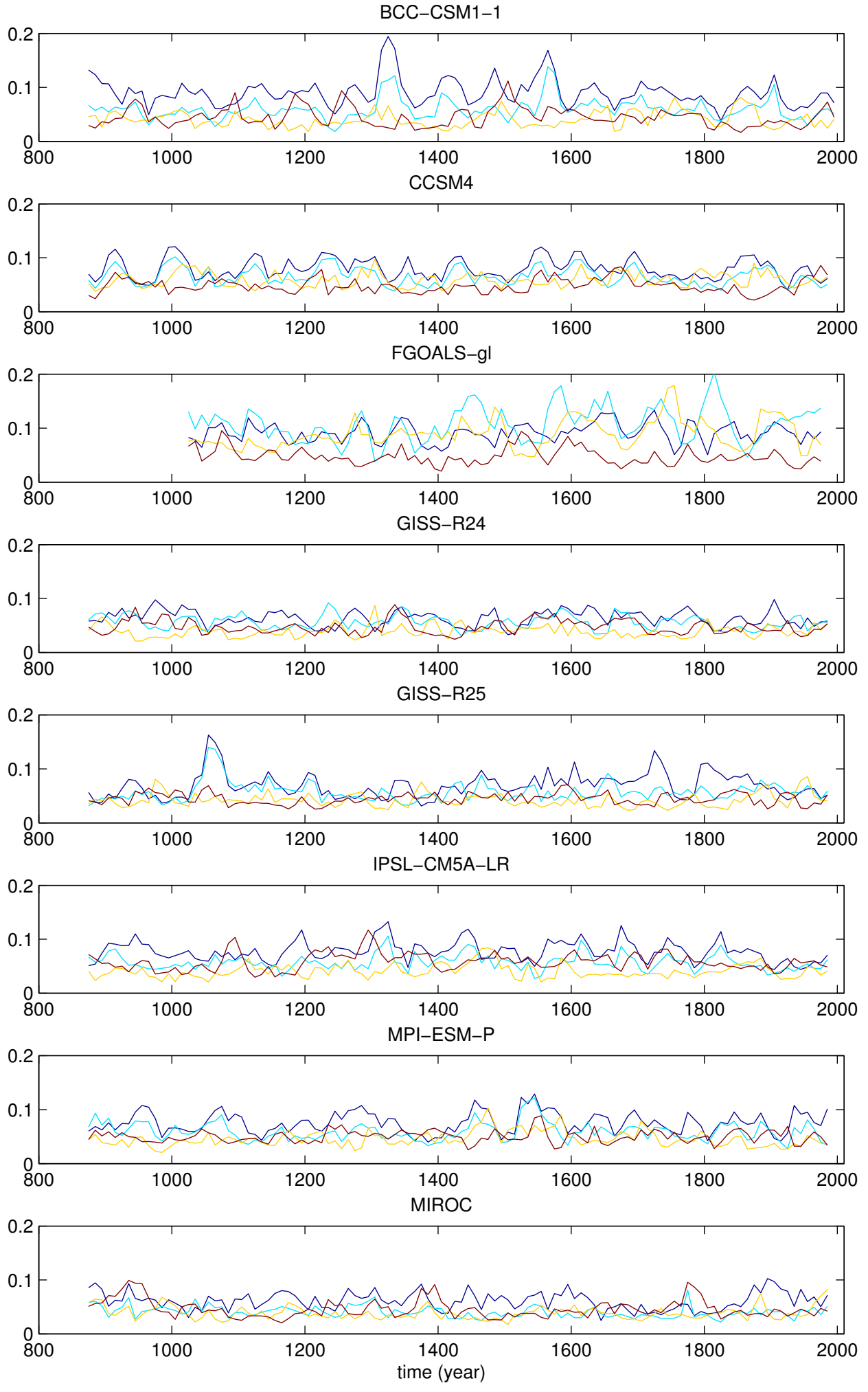

$\longrightarrow$ PNA NPI SOI NAO

Figure S7 - Fractions of total variance of winter North American precipitation (land only grid points within the domain $20-70^{\circ} \mathrm{N}, 190-300^{\circ} \mathrm{E}$ ) explained by winter PNA, NPI, NAO and SOI indices for individual simulations. Values are calculated over decadally-paced 30-year periods. 

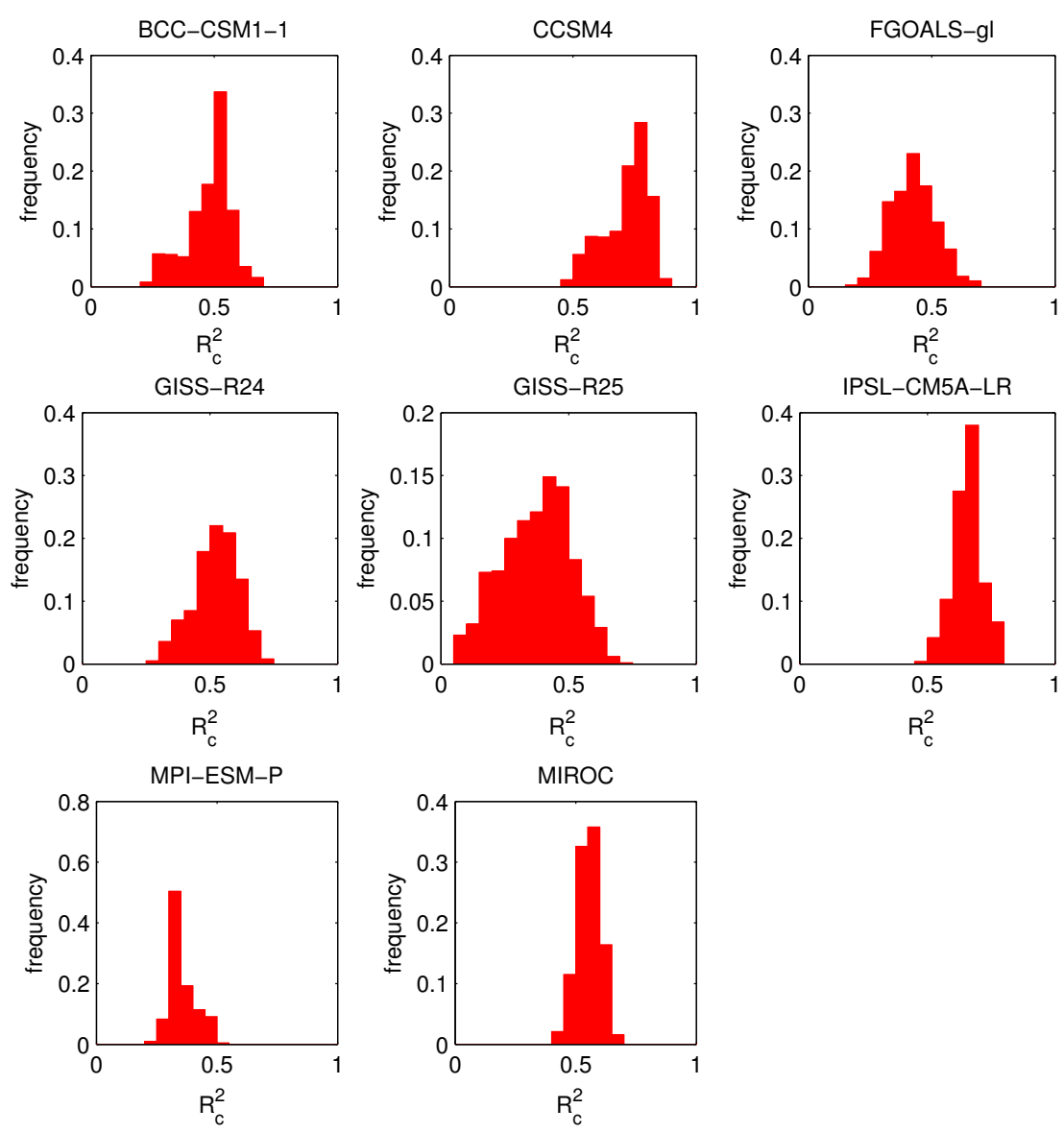

Figure S8 - Empirical probability distributions of calibration $\mathrm{R}^{2}$ values for the full ensemble of TT2010-like PNA pseudo-reconstructions for individual simulations, from which pseudoreconstructions illustrated in Figures $7 \mathrm{a}, \mathrm{b}$ and 8 in the main manuscript are sampled. Note that the $\mathrm{y}$ axis has different scales in the different panels. 

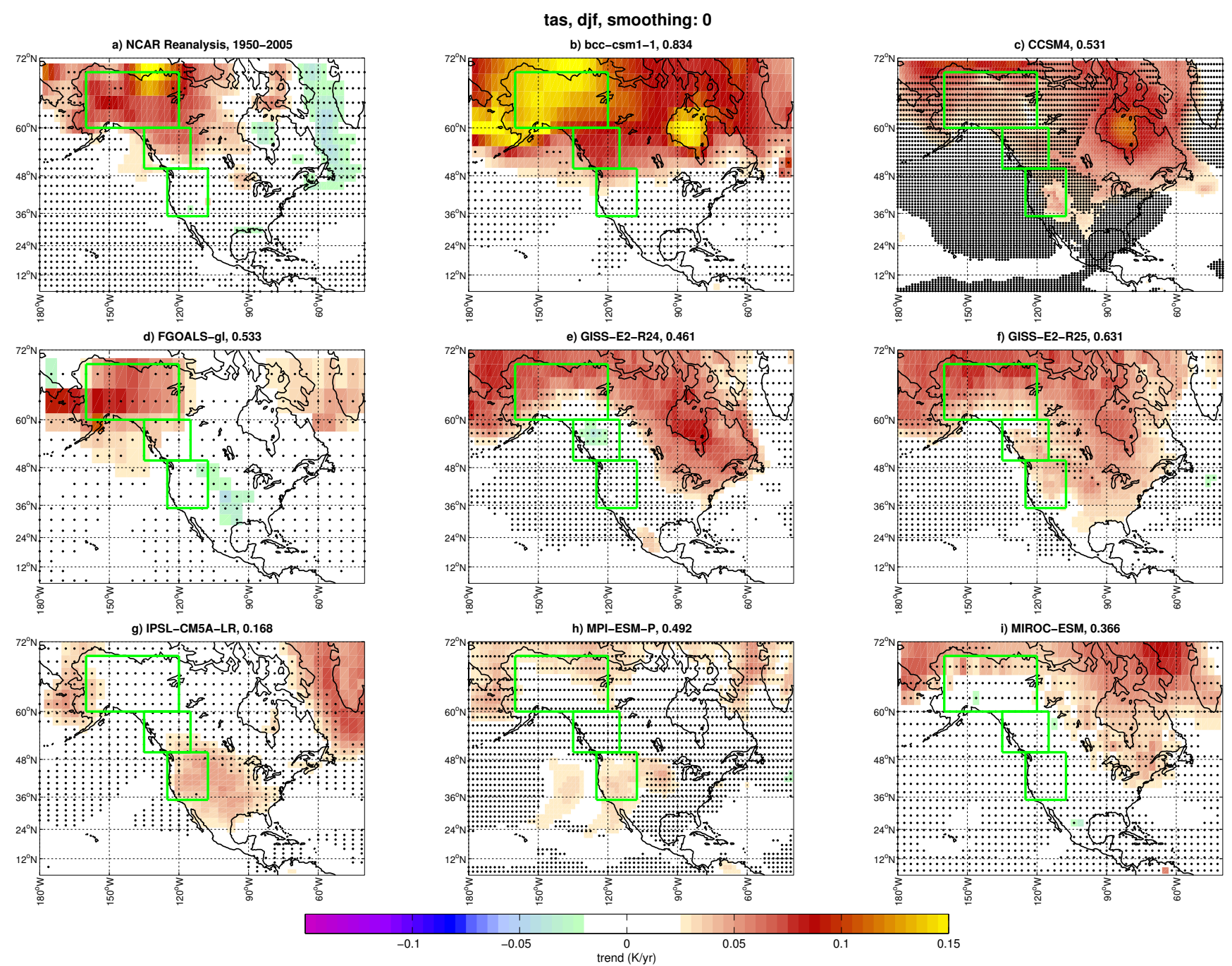

Figure S9 - Trends of North American winter surface air temperatures during the period 1950-2005 in NCAR reanalysis (panel a) and historical simulations (panels b-f). Dots mark grid points where the trend is not significant at $95 \%$ confidence accounting for autocorrelation. The green contours mark the boxes used for the TT2010 reconstruction. The numbers on panels for simulations are the spatial correlations between observed and simulated patterns calculated for the shown land-only domain north of $12^{\circ} \mathrm{N}$ (to this purpose NCAR data were regridded to the model grid). 

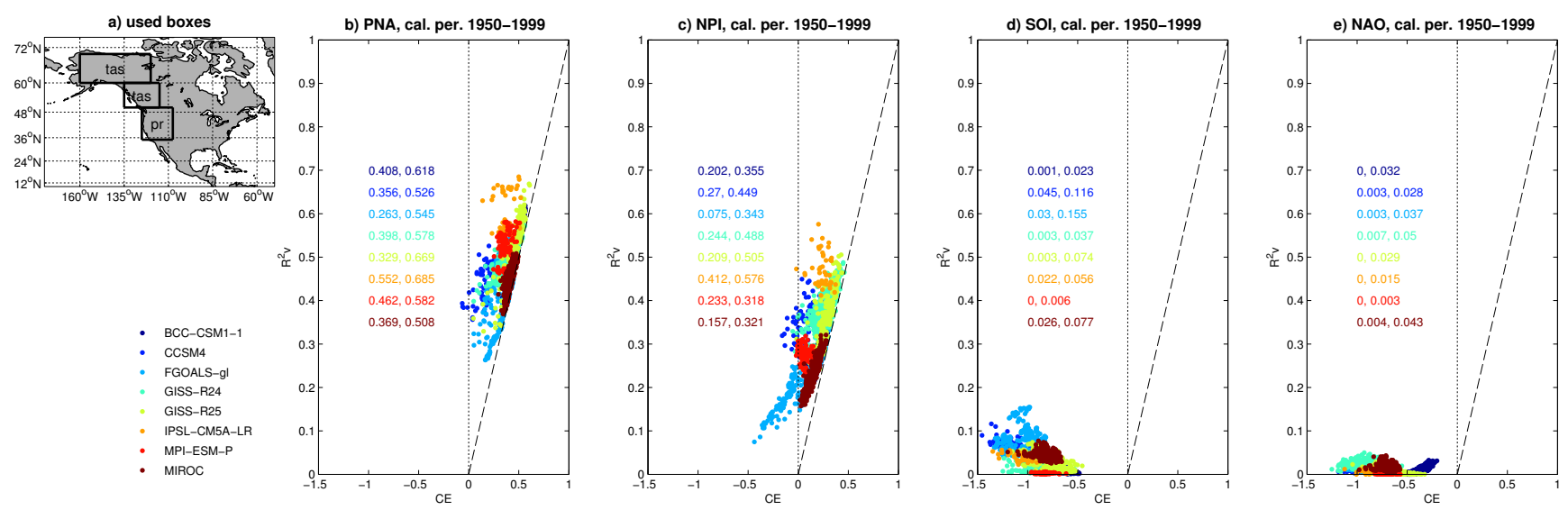

Figure S10 - Skill metrics for an ensemble of TT2010-like reconstructions following Figure 7a: a) map of the three boxes from where gridded data are sampled to be included as predictors, with the name reported in each box (tas: surface air temperature, pr: precipitation); b-e) full-validation period coefficient of determination $\left(\mathrm{R}^{2} \mathrm{v}\right)$ and coefficient of error (CE) for the reconstructions using respectively the winter PNA (b), NPI (c), SOI (d) and NAO (e) as predicted variable. For each reconstruction, the regression model is always calibrated on PNA, see methods. To be comparable with TT2010, only the subset of reconstructions with $\mathrm{R}^{2}$ for the PNA for the 1950-1999 calibration period in the range [0.45-0.55] are considered $\left(\mathrm{R}^{2} \mathrm{c}=0.49\right.$ in TT2010). The numbers inside each panel indicate the minimum and maximum $\mathrm{R}^{2} \mathrm{v}$ values obtained for each model.
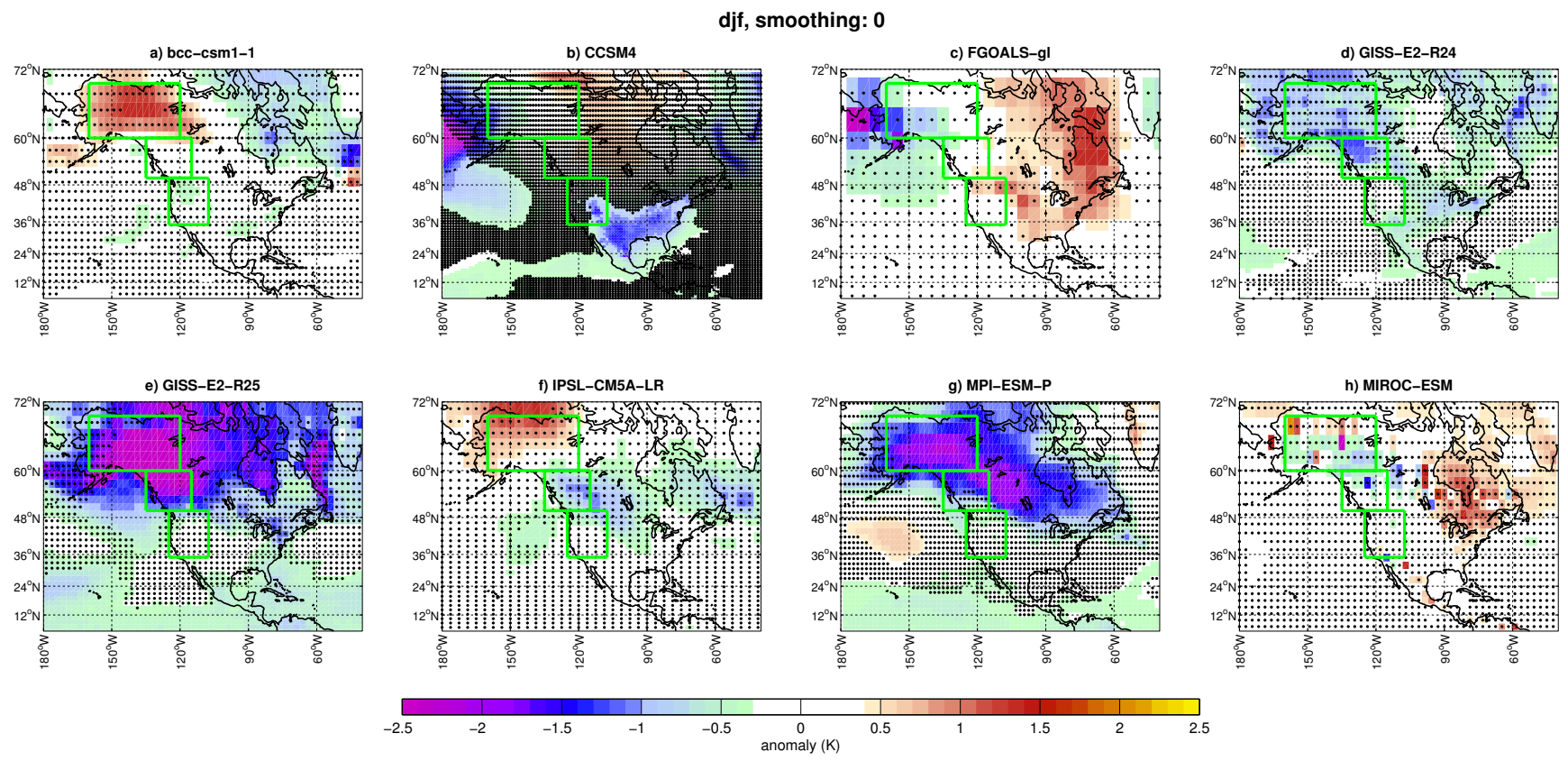

Figure S11 - Winter (djf) surface air temperature anomalies for the period 1800-1820 from the preindustrial climatology. Dots mark grid points where the anomaly does not exceed the $5^{\text {th }}-95^{\text {th }}$ percentile range of 21-year running mean anomalies for the pre-industrial period. The select period corresponds to the approximate duration of the early-19 $9^{\text {th }}$-century positive PNA phase in the TT2010 reconstruction. 

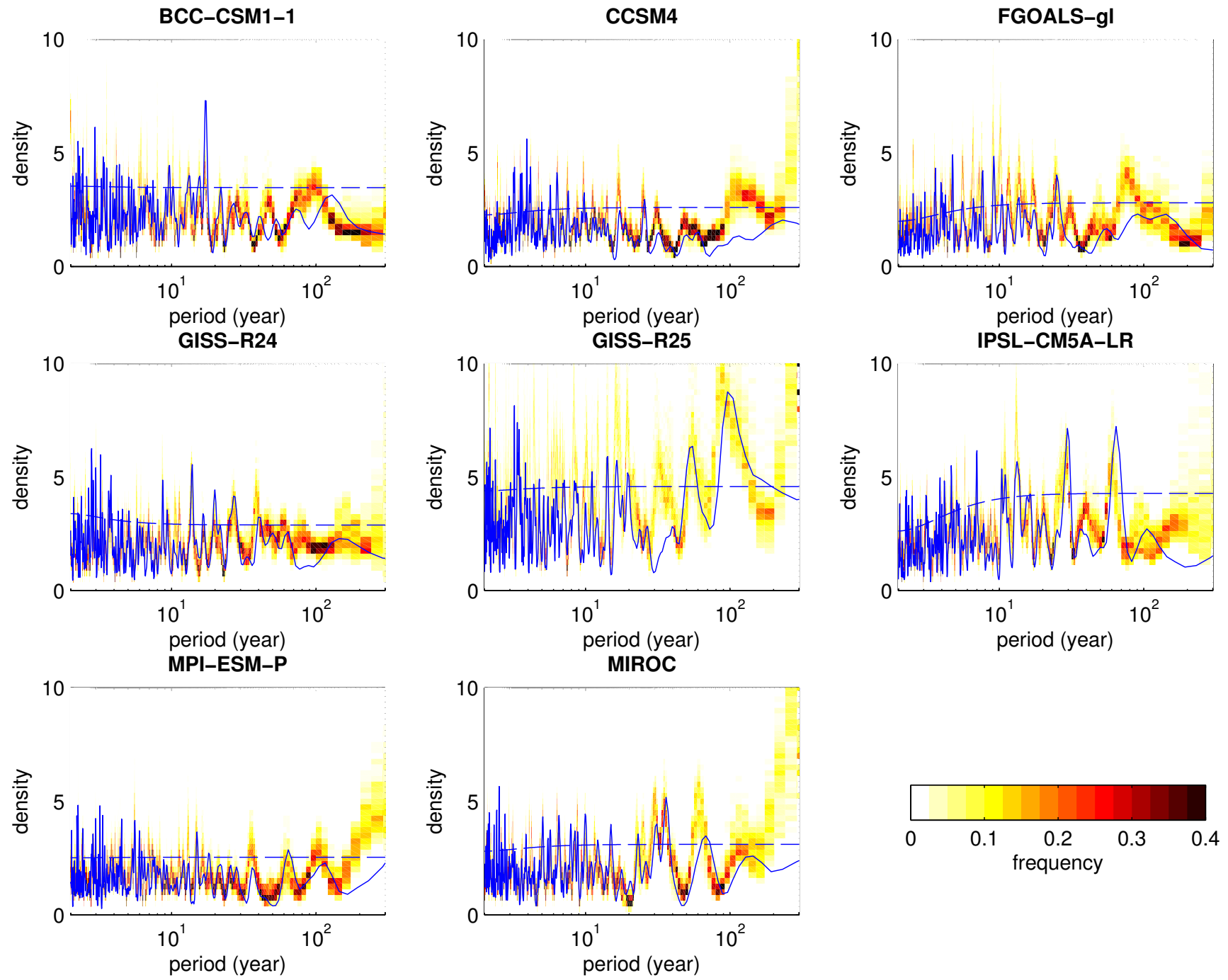

Figure S12 - Power spectral density of the winter PNA index (blue line) for individual simulations with associated 95\% confidence level (blue dashed line) and agreement between the spectra of the pseudoreconstructions obtained following the modified TT2010 approach (including a box over Florida and extended calibration period) and illustrated in Figure $7 \mathrm{c}$ of the main paper. All indices are standardized according to the 1950-1999 climatology. 

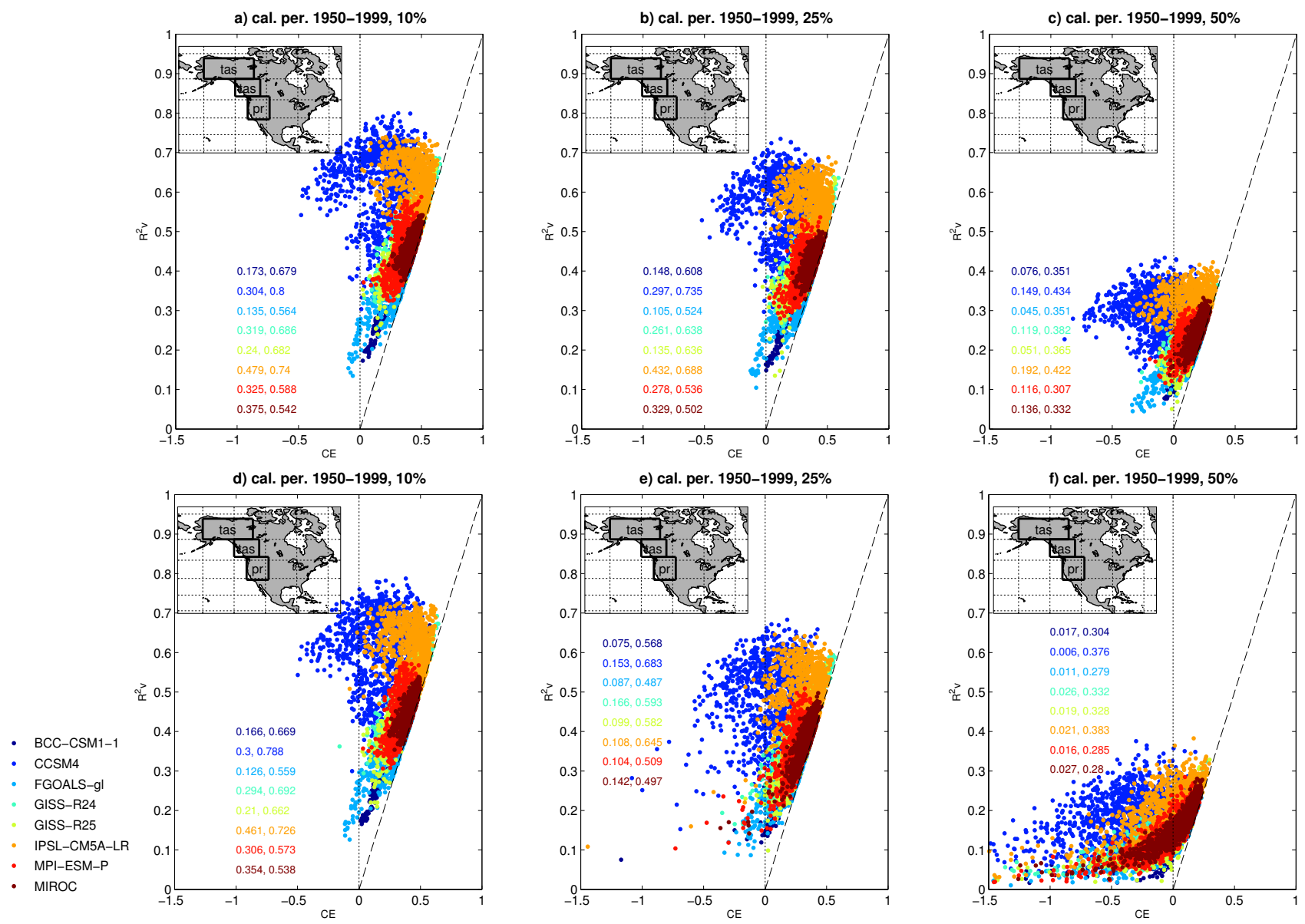

Figure S13 - Skill metrics for an ensemble of TT2010-like reconstructions following Figure 7b but highlighting the impact of predictors' noise on the pseudo-reconstructions. Different panels illustrate results from different types and levels of noise, which is only added for the validation period. Top: white noise; bottom: red noise. Noise contributes to $10 \%(\mathrm{a}, \mathrm{d}), 25 \%(\mathrm{~b}, \mathrm{e})$ and $50 \%(\mathrm{c}, \mathrm{f})$ of the predictors' total variance. Results are for 1000 pseudo-reconstructions without pre-selection of predictors based on calibration skills. The numbers inside each panel indicate the minimum and maximum $\mathrm{R}^{2} \mathrm{v}$ values obtained for each model. Insets in each panel map the three boxes from where gridded data are sampled to be included as predictors, with the name reported in each box (tas: surface air temperature, pr: precipitation). Red noise is assumed to be an autoregressive lag-1 process, generated following von Storch et al. (2009). Specifically, the value of the lag-1 autocorrelation is drawn at random from a beta distribution (parameters 7 and 3), in the interval $(0,1)$.

Ref.: von Storch, H., E. Zorita, F. González-Rouco (2009) Assessment of three temperature reconstruction methods in the virtual reality of a climate simulation. Int. J. Earth. Sci. (Geol Rundsch) 98:67-82, doi:10.1007/s00531-008-0349-5 


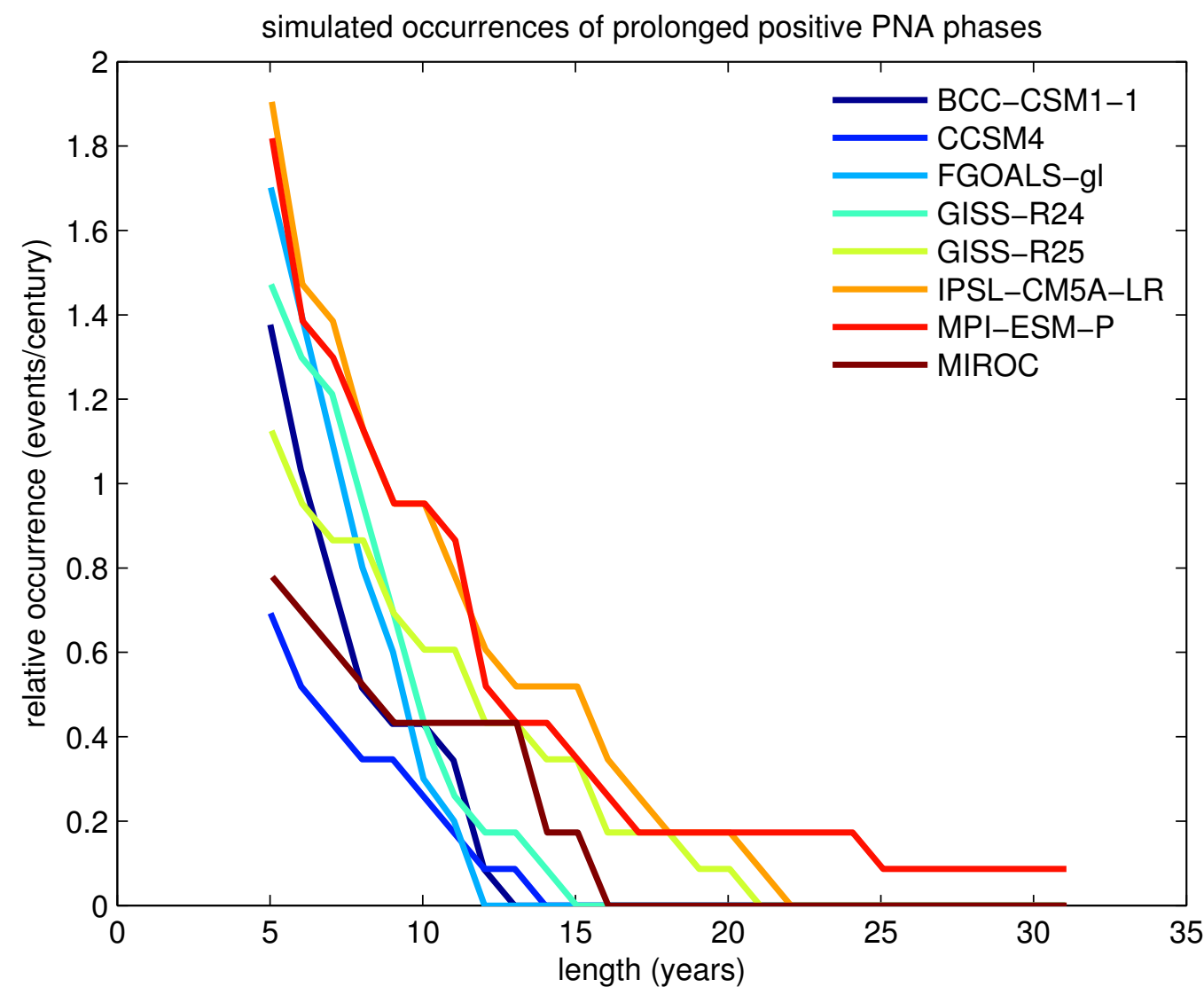

Figure S14 - Relative occurrences of prolonged positive PNA phases in the different simulations. An event of duration $l$ is individuated when the standardized (with respect to the period 1725-1999) smoothed PNA index (11-year running mean) remains above the value of 1 for $l$ consecutive years. Results may differ from those illustrated in Figure 4 of the main manuscript due to the different period used for the standardization of the PNA indices. 


\begin{tabular}{|c|c|c|c|}
\hline Simulation & $\begin{array}{l}\text { explained } \\
\text { variance }(\%)\end{array}$ & $\begin{array}{l}\text { Temporal correlation with } \\
\text { mpm index (1949-2005) }\end{array}$ & $\begin{array}{l}\text { Spatial correlation with } \\
\text { NCAR Reanalysis pattern } \\
\left(\text { north of } 20^{\circ} \mathrm{N}\right)\end{array}$ \\
\hline BCC-CSM1-1 & 20.7 & $0.885(<0.0001)$ & 0.74 \\
\hline CCSM4 & 36.1 & $0.961(<0.0001)$ & 0.86 \\
\hline $\begin{array}{l}\text { FGOALS-gl } \\
\text { (up to year } \\
\text { 1999) }\end{array}$ & 28.1 & $0.731(<0.0001)$ & 0.45 \\
\hline GISS-E2-R24 & 21.7 & $0.756(<0.0001)$ & 0.56 \\
\hline GISS-E2-R25 & 22.6 & $0.679(<0.0001)$ & 0.52 \\
\hline $\begin{array}{l}\text { IPSL-CM5A- } \\
\text { LR }\end{array}$ & 17 & $0.948(<0.0001)$ & 0.79 \\
\hline MPI-ESM-P & 18.5 & $0.868(<0.0001)$ & 0.8 \\
\hline MIROC-ESM & 23.43 & $0.678(<0.0001)$ & 0.72 \\
\hline
\end{tabular}

Table S1 - Statistics of winter PNA indices calculated as the principal component of the first empirical orthogonal function of linearly detrended winter (djf) geopotential height data at $500 \mathrm{hPa}$ for the period 1949-2005, over the domain $\left[0-90^{\circ} \mathrm{N} ; 120-300^{\circ} \mathrm{E}\right]$. The explained variance of the EOF-based index calculated from NCAR Reanalysis data is $19.35 \%$, and its correlation with the modified pointwise method-based index is $0.934(\mathrm{p}<0.0001)$. 